\title{
Un ciclo solar del cuento en México
}

\author{
Blanca Rodríguez \\ Facultad de Filosofía y Letras, \\ Universidad Nacional Autónoma de México
}

El objeto de esta exposición es informar críticamente sobre el contenido del libro Cuento muerto no anda (La ficción en México) (Muñoz 2004), que comenzó a circular a principios del año 2005 y que examina, valora y critica la escritura del cuento en México durante los años que transcurren entre 1950 y 2003. La obra comprende dieciséis ensayos especializados a cargo de igual número de distinguidos investigadores del cuento que se han dedicado a su estudio y crítica.

Previo a entrar en materia, juzgo necesario ubicar los antecedentes de la obra. En 1989, la Universidad Autónoma de Tlaxcala se convirtió en la sede del I Encuentro de Investigadores del Cuento Mexicano, en conjunto con la Universidad Autónoma de Puebla, el Instituto Nacional de Bellas Artes y el Consejo Nacional para la Cultura y las Artes. Quince Encuentros se sucedieron año tras año en esa institución hasta 2003, año de su clausura en Tlaxcala, por lo que el XVI Encuentro tuvo lugar en la Universidad de California en Santa Bárbara, en octubre de 2004, donde se rindió homenaje al fundador de los estudios de la materia, don Luis Leal, nacido en 1907 en Linares, Nuevo León. ${ }^{1}$ En 1990, además, se inició la edición de la Serie Destino Arbitrario, que fue el órgano editorial de los Encuentros, aunque también acogió obras específicas sobre la materia ${ }^{2}$

\footnotetext{
1 "In Honor of Luis Leal", VII Colloquium on Mexican Literature / XVI Encuentro de Investigadores del Cuento Mexicano / Segundo Encuentro Binacional del Cuento Mexicano, University California of Santa Bárbara, october 28-30, 2004.

${ }^{2}$ Entre ellas destaca Breve historia del cuento mexicano de Luis Leal (1990). La Universidad Autónoma de Puebla participó en la organización y coediciones de los tres primeros encuentros (Cluff 2003).
} 
que a la fecha suman 23 volúmenes que pueden calificarse como una enciclopedia sobre el cuento, en la cual se incluye el indispensable Panorama crítico-bibliográfico del cuento mexicano (1950-1995), de Russell M. Cluff (1997). ${ }^{3}$ Una de las virtudes de los Encuentros fue la inmediata publicación de sus memorias, editadas por Alfredo Pavón, pues cuando sucedía el siguiente, ya se disponía del libro correspondiente al anterior, de modo que el libro que se aborda está al día, tarea por demás insólita en nuestro medio. ${ }^{4}$

Paso ahora a referirme a los parámetros de la obra en cuestión. ${ }^{5} \mathrm{El}$ período que cubrió el XV Encuentro abarca el estudio del cuento de 1950 a 2002; de ahí mi idea de estar frente a un ciclo solar de 52 años, sin embargo, si nos atenemos a la lectura del prólogo, encontramos en voz de Alfredo Pavón que: "Cuento muerto no anda es, ante todo, una apertura. Busca el diálogo con escritores, críticos, lectores. Elige un tema: la cuentística mexicana publicada entre 1950 y 2003" (Muñoz: ix), por lo que son, en realidad, 54 años de estudio del género. El título del libro, por sí mismo, no es indicativo en primer término de su contenido, a menos que ya se haya leído y en ese caso lo oculto se manifiesta, pues los textos individuales son los que darán noticia de su intención. Por ejemplo, Luz Elena Zamudio Rodríguez comunica que el XV Encuentro "fue el preámbulo para la realización, en equipo, de un intento conjunto por ordenar la historia del cuento mexicano"; a su vez, Lauro Zavala alude a la importancia del año 1968 "en la historia del cuento" y en la "historia reciente del cuento mexicano" $(81,137,160)$. Dichas afirmaciones esclarecen el objetivo de sus estudios y, por ende, el de casi todo el equipo, así como la intención de que estuvieran dirigidos al lector especializado y a aquellos interesados en el asunto, de acuerdo con Pavón. De hecho, el punto

\footnotetext{
${ }^{3}$ Gracias a esta obra pudo emprenderse el estudio que nos ocupa y se cita constantemente. Su estudio "Panorama crítico-histórico del nuevo cuento mexicano", que precede a los distintos índices que integró, sirve de expresión compacta de las ideas y juicios que ha generado en sus numerosos ensayos críticos sobre el cuento mexicano.

${ }^{4}$ Para un recuento sobre los diez primeros encuentros puede consultarse: Díaz Ruiz 1999; y Urbina Orantes 2001, quien aborda aspectos teóricos e históricos e información clasificada sobre cuentistas estudiados y expositores; una síntesis se encuentra en Urbina Orantes 2003: 1-21.

${ }^{5}$ En adelante, la primera mención sobre un crítico o un autor registrará su nombre completo y después, sólo su apellido, siempre que no cause confusión.
} 
de partida del libro en cuestión se empalma con tino donde concluye la obra pionera del maestro Luis Leal, que abarca "desde sus orígenes hasta 1955" (1990), sólo que por la cantidad de escritores, libros y su profunda calidad en la segunda mitad del siglo xx, hubiera sido imposible abordar la cuentística mexicana desde el trabajo de una sola persona. El hecho de que el prólogo no revele objetivos, método o métodos, propósitos, carencias y alcances o resultados, no implica su ausencia, pues en cada estudio su responsable lo manifestó en una forma u otra. De tal manera que ahora se comprende aquello que el título afirma negándolo: el cuento mexicano se encuentra en estado viviente, o, con el sabor de nuestra expresión popular, diríamos que está más vivo que nunca.

\section{CRITERIOS PARA LA REALIZACIÓN DE LOS ESTUdios ${ }^{6}$}

La participación de los especialistas tuvo como base el compromiso de qué investigadores estaban dispuestos a realizar su trabajo en forma

\footnotetext{
${ }^{6}$ Los enumero de acuerdo con el Índice: [Años 50.] Mario Muñoz. "En los umbrales del medio siglo: 1950-1953". 1-42; Edith Negrín. "Cuentos para vencer a la muerte: 1954-1957". 43-80; Luz Elena Zamudio Rodríguez. "Varias direcciones de escritura: 1958-1961". 81-109. [Años 60.] Luz Elena Gutiérrez de Velasco. "Inminencia total: 1962-1965". 111-131; Lauro Zavala. "El cuento irónico moderno: 1966-1969 (Prefiguración del cuento posmoderno: 1988-1990)". 133-151. [Años 70.] Laura Cázares H. "Los demasiados cuentos: 1970-1973". 153-194; Russell M. Cluff. "Modalidades y estrategias: 1974-1977". 195-253; Vicente Francisco Torres. "Fantasía y poeticidad: 1978-1981". 255-265. [Años 80.] Elizabeth Corral Peña. "La escritura de los viajes: 1982-1984". 267-294; Jaime Erasto Cortés. "Tres años de producción (1985-1987), quince de Encuentros, sesenta y cinco de edad". 295-310; Miguel G. Rodríguez Lozano. "De cuentos y cuentistas: 1988-1990". 311-329. [Años 90s.] Ana Rosa Domenella. "Los demasiados cuentos: 1991-1993". 331-372; Pablo Brescia. "Una página de la cuentística mexicana: 1994-1996 (Registros narrativos y el margen de las mujeres)". 373-393; Federico Patán. "El cuento halla siempre sus veredas: 1997-1999". 395-411. [Años 2000] Sara Poot Herrera. "El lector se acerca a su cuento: 2000-2002". 413-488; Alfredo Pavón. "El breve espacio donde no estás" [Reseña crítica de Antologías]. 489-530. [Ensayos de los cuentistas]: Mauricio Molina. "De ornitorrincos, fractales y hoyos negros (Algunas indicaciones sobre el cuento)". 531-538; Ana Clavel. "Poética de la sombra". 539-543; René Avilés Fabila. "El cuento y yo, una relación de intenso amor". 545-562 y Federico Patán. "Y ¿̨cómo se escribe un cuento?". 563-574 (Muñoz).
} 
completa y segura, en lo cual también medió su pasión por el tema. Asegurado esto, supongo que se escogieron los períodos tanto por preferencia personal como por su conocimiento previo en docencia o en publicaciones, aunque también pudo ser cuestión de suerte. Deduzco que el primer problema al que ellos se enfrentaron, lo confiesen o no, se relacionó con las razones para incluir o descartar obras y autores, lo cual impuso a cada uno fijar sus estrategias, anunciadas en breves o múltiples renglones, a mi juicio en la mayor parte razonables y válidas. Quien lee quizá se pregunte si hubo un consenso general preestablecido. Infiero que la respuesta es que, si bien todos ellos habían contribuido eficaz y valiosamente a los estudios sobre el cuento, sus trabajos provienen tanto de inclinaciones personales justificadas como de la temática abordada en previos encuentros. Los investigadores, por otra parte, no son miembros de un seminario específico que se reúna en sesiones un determinado número de veces por año. Esa labor la cumplieron los Encuentros, particularmente por el espacio de diálogo formal e informal que se generaba tanto en los debates al término de las exposiciones, como en los gratos momentos de convivencia a la hora del café o de las comidas. Además, en sus actividades dentro de las renombradas universidades en que trabajan, con frecuencia encuentran otros espacios de reflexión, como pueden ser la cátedra, tutorías, conferencias y publicaciones. Fue su presencia a lo largo de varios Encuentros lo que los impulsó a comprometerse motu proprio, ya que de antemano se conocía lo arduo que sería el trabajo por la búsqueda de fuentes de primera mano, lectura y relectura, conocimiento del contexto, clasificación, valoración crítica, etcétera. Así, cada investigador tuvo la libertad de establecer sus criterios (determinados, incluso, por su corpus), por lo que el lector encontrará acentos particulares sin menoscabo de la riqueza del contenido y en buena parte armonizados con el resto de los trabajos.

Entre otras razones, Mario Muñoz reconoce el riesgo de "ponderar unas obras y disminuir otras" en el corpus abordado y expone los riesgos, entre ellos, su naturaleza incompleta y la falta de una clasificación orgánica de las varias orientaciones en temas y en estructuras del cuento moderno. Luz Elena Zamudio Rodríguez advierte sobre el lugar que puede ocupar un libro en la escritura total del autor y el resultado de la valoración del crítico, que incluso puede hallar rastros de la na- 
rrativa decimonónica o bien, influencias de carácter extraliterario. Luz Elena Gutiérrez de Velasco se enfoca hacia la búsqueda de rupturas y transiciones a través de la forma de escribir. Russell M. Cluff indaga sobre la conciencia de las modalidades, incluso las genéricas, y las estrategias de la cuentística de su período, a las que suma la calidad de lectura que pudiera alcanzarse. La selección de Vicente Francisco Torres es precisa y selectiva por cuanto persigue la absoluta calidad estética del cuento, en el que privilegia el lenguaje, recursos narrativos de primer orden y le apasionan atmósferas fantásticas o insólitas. Lauro Zavala considera su trabajo como una relectura que fructifica en una antología y en su corpus privilegió la calidad "prefigurativa" de los cuentos que se escribirían veinte años más tarde, durante el período 1988-1990, abordado por Miguel G. Rodríguez Lozano, quien ofrece un "breve y general panorama" en lo posible de los menos citados — para no redundar en la anticipación hecha por Zavala- y estudiados "con el fin de ampliar el mapa de la cuentística". Por la extensión del material bibliográfico, Laura Cázares decidió incluir "la mayor cantidad de autores posible y agruparlos" por generaciones, aunque aclara que dicho concepto pudiera ser discutido. De manera similar, Ana Rosa Domenella procede a reunir generaciones de escritoras porque "primero las damas" y luego los aborda a ellos, "los conocidos, los imprescindibles y pocos más".

Elizabeth Corral, consciente de "la arbitrariedad de toda clasificación”, se apega a las obras más significativas para el lector actual agrupándolas por su temática y, en concordancia con Cázares y Domenella, integra las previas aportaciones críticas de Leal, Cortés, Pavón, Cluff y Poot Herrera sobre el período, que "no ha ido a la zaga". Jaime Erasto Cortés se pliega a un modelo ya experimentado: selecciona una obra, procede a examinar la crítica en el momento de su aparición y señala cómo es superada al paso del tiempo en aquello que se juzgó impropio, lo cual da pie a una breve exposición, sustanciosa e irónica, sobre la crítica. Pablo Brescia compara las cifras de publicaciones de libros de cuentos de acuerdo con el género; como los de ellas son menos, se propuso descifrar "una historia algo oculta" que lo inclinó por dos obras solamente: el resto lo lega al "análisis futuro" pues "el objetivo de estas páginas es otro", decisión que lo aparta de la tónica general. Federico Patán detecta que el margen de diferencia entre los cuentistas de ambos sexos se ha reducido en forma considerable y en ello se 
distingue "una visión femenina de la existencia humana"; asegura, además, que en su período coexisten "varias generaciones de cuentistas que trabajan al unísono”. El trabajo de Sara Poot Herrera se inicia en la forzosa lucha que el cuento emprende de cara a la preferencia editorial por publicar novela y ello le da pie para realizar un balance cultural. La intervención de cierre corresponde a Pavón, que hace una valoración global del contenido de las antologías que inciden antes y después del siglo Xx. Para la conclusión de este apartado, reservé la persona de Edith Negrín, quien al rigor sumó la emoción con respecto del género. La especialista considera al discurso social un "inmenso rumor fragmentado, disonante, contradictorio", del cual se tiene un atisbo dentro de la literatura, y declara: "un grupo de compañeros nos propusimos escuchar el sonido y la furia producidos por un solo género literario, el cuento, un único género, cuya enorme flexibilidad y riqueza, cuyas ilimitadas posibilidades ofrecen [...] un conjunto fascinante, donde cada una de las partículas es una unidad de sentido." Cada uno de los investigadores en sus palabras nos han transmitido la pasión del grupo por su trabajo, en el sentido que, de acuerdo con Mario Muñoz, propone un personaje de Bioy Casares, "una emoción, indudablemente, es una forma humildísima de crítica” (42).

\section{CONTENIDO DE LOS TRABAjOS}

Con la suma de los motivos que cada especialista expuso, el libro dispone ahora de varias rutas complementarias para acercarnos a su contenido. Para facilitar la exposición de las apreciaciones críticas de los investigadores, en este apartado los reagrupé por períodos decenales, a efecto de establecer cinco conjuntos para el siglo xx y otro para el incipiente siglo XXI y las antologías. Externo que cada autor es respetado en su período e ideas y que esta intervención es una reseña crítica e incluso apretada sobre su contenido, por lo que tuve que excluir aspectos que los expertos podrían llegar a reclamar como necesarios. Por mi parte, no mentiría si dijera que cada uno merecía una exposición específica, pues cada estudio impone la necesidad del diálogo con ese lector magnífico que a lo largo de su vida se ha recreado con centenares de libros de cuento. 


\section{LOS AÑOS CINCUENTA:}

Mario Muñoz, Edith Negrín y Luz Elena Zamudio Rodríguez

La segunda mitad del siglo XX se encuentra privilegiada desde su inicio ya que durante sus primeros años aparecieron cuatro libros modelo: sobre dos, Confabulario de Juan José Arreola y El llano en llamas de Juan Rulfo, Muñoz integra un inteligente y somero juicio crítico, persuasivo para viejos y nuevos lectores. Del tercero, El diosero de Francisco Rojas González, el crítico resalta su orientación indigenista; y del cuarto, Tapioca Inn. Mansión para fantasmas de Francisco Tario, su condición fantástica. Estos dos autores, al lado de Jesús Martínez Sotomayor (en El reino azul, de orientación urbana y con personajes de sugerente interioridad), debieron esperar décadas para figurar en la crítica. Muñoz teje una red de correspondencias entre lo histórico-social y la literatura, observando varias orientaciones para el cuento: unas ya mencionadas en lo precedente y otras insertas en el ambiente rural o revolucionario — como en las obras de José Mancisidor ( $\mathrm{La}$ primera piedra) y Jorge Ferretis (El coronel que asesinó un palomo...)o la fantástica y cosmopolita con Arreola, Tario y Tito Monterroso, que aparece en forma casi imperceptible en ediciones de 1951 y 1953. En la veta experimental se encuentra Rubén Salazar Mallén (Ejercicios), que incide en las primicias de orientación metaliteraria de Juan Vicente Melo (La noche alucinada), y en la tradición "del realismo psicológico" en Sergio Galindo (La máquina vacía). El autor se detiene en piezas significativas de cada cuentario para examinar cuidadosamente sus recursos literarios, lo cual indica su dominio sobre los mecanismos secretos del cuento. Ante sus exposiciones, uno duda en descifrar quién sería su cuentista preferido, vistas las figuras trascendentales para nuestra literatura desde esos años, Arreola y Rulfo; sin embargo, el hecho de que el último aparezca como cierre de su ensayo y declare que "desde la óptica de la actualidad [su obra completa] anticipa la decadencia de la modernidad, cuando paradójicamente, México apenas comenzaba a ingresar en una era de crecimiento", nos proporciona la clave de su preferencia.

La exposición de Negrín se inicia con un resumen de índole histórico-política, incluida por la mayoría de los estudiosos, aunque en caso de ausencia en forma alguna invalida el período en cuestión. En 1955 aparece Quince presencias de Alfonso Reyes, quien selecciona algunas 
narraciones escritas entre 1915 y 1954 , libro que le permite a la investigadora resaltar al escritor en el escenario del cuento, pues observa que en su escritura se hallan "a veces la realización y a veces el germen, de las principales tendencias cuentísticas en la literatura mexicana del siglo Xx". Procede a revisar piezas realistas, fantásticas o testimoniales, algunas con vetas de fino humor, y a indagar por qué, desde la perspectiva actual, su escritura ha sido de largo alcance: avala su imbricación de géneros, en que la reflexión, la confrontación de ideas o la citación de fuentes lo llevan a crear el "cuento ensayo" y destaca sus recursos metaficcionales (aquí: un binomio afortunado: Reyes-Borges y viceversa) y la intertextualidad como juego literario; concluye afirmando que Reyes "es capaz de desnudarse de su erudición para alcanzar" lo que Jaime Erasto Cortés define como "la límpida naturaleza del cuento". Con Negrín se inicia el rescate de las cuentistas, siempre que exista un motivo social o estético logrado, como sucede en María Lombardo de Caso y Carmen Rosenzweig, vertiente con que simpatiza la mayoría de los críticos. Le parece que el realismo es todavía "el vehículo más apropiado para ejercer la denuncia social” durante los años 50, por ello, toma en consideración la literatura sobre indígenas, campesinos, migrantes, etcétera, y la perspectiva de los militantes, como José Mancisidor; atiende, así mismo, a cuentistas que crean un universo con la infancia, como Guadalupe Dueñas, Elena Poniatowska y Jorge López Páez. La muerte tiene permiso recibe atención, igual que su autor, don Edmundo Valadés, el alma de los Encuentros de Tlaxcala y de la Serie Destino Arbitrario. Por último, entre los narradores modernos incluye a Ricardo Garibay, Melo — quien alcanza "la perfección formal" - José de la Colina — de larga y fructífera escritura- y Carlos Fuentes, quien con Los días enmascarados reinaugura el ámbito fantástico, en el cual hasta 1988 Tario alcanzaría el reconocimiento.

Juzga Zamudio Rodríguez que Tiene la noche un árbol de Dueñas es "ya una manifestación de la profecía postulada por Leal: en esta obra se unen las tendencias realista e impresionista”. Beatriz Espejo, José Emilio Pacheco y Sergio Pitol se inician publicando en 1958, bajo el sello de Cuadernos del Unicornio, editados por Arreola. Es Pacheco quien sirve de amanuense al maestro para que publique, a su vez, Bestiario. Junto con De la Colina, Max Aub destaca entre los transterrados, y Monterroso, con Obras completas (y otros cuentos) "es 
otro de los grandes regalos literarios". Por último, broche incomparable, aparece Dormir en tierra de José Revueltas. Como Negrín, Zamudio ha rescatado a algunas cuentistas menores y ha recuperado el nombre de Xavier Vargas Pardo, cuyo Céfero elogió Valadés (59-64) y avaló Rulfo. Debido al carácter fragmentario e irregular del objeto de estudio, Zamudio estima sus conclusiones con carácter parcial, pero plantea su posible utilidad al expresar las direcciones que tomó el cuento durante el período. Aunque siguen presentes formas realistas provenientes del siglo XIX, distingue la madurez de Amparo Dávila y Arreola y elogia los bestiarios de éste y de Dueñas.

\section{LOS SESENTA EN OCHO AÑOS:}

\section{Luz Elena Gutiérrez de Velasco y Lauro Zavala}

En un país cimbrado por el movimiento ferrocarrilero y el de los médicos, Gutiérrez de Velasco detecta el surgimiento, en el campo literario, de una nueva escritura que se relaciona con la generación de la Casa del Lago, "los que se empeñaron en hacer del cuento un vehículo" de "experimentos formales y temáticos", junto con el ascenso de jóvenes que sus lectores identificamos como la "Onda", aunque ellos rechacen esta convención, y con la presencia de numerosas mujeres en la cuentística que "permanecen con honores". Gutiérrez de Velasco enumera, para situar las dimensiones de la narrativa de ese lapso, dieciséis novelas señeras en las que encuentra "nuevas fórmulas de expresión de identidad personal y de nación” y correlativamente, enumera los libros de cuentos con nuevas posibilidades expresivas. La especialista los reagrupa por ópera prima o por segunda llamada, por reunión de piezas dispersas o reedición, para abordarlas después por tema, pero, sensible a los cambios en la sociedad, escribe un trabajo en que, respetuosa de la enumeración y descripción que distingue a este tipo de obras, logra fusionar numerosas ideas originales y juicios sensibles.

\footnotetext{
${ }^{7}$ Registro aquí las alusiones a la "generación de Medio Siglo" como de "la Casa del Lago". Cfr. Huberto Batis, "El más firme y antiguo de mis amigos", en Posdata. Suplemento Cultural de El Independiente 27 (10 enero 2004). 5-7. "No nos gusta que nos llamen "de los 30"” [...], ni de "Medio Siglo" [...] Se ha ido imponiendo que nos llamen la "generación de la Casa del Lago" o de "la Revista Mexicana de Literatura".
} 
Entre los temas que llamaríamos tradicionales, en su inicio se refiere a la oposición campo/ciudad, aún vigente en Agustín Yáñez, y luego, a la infancia con algunas piezas de Pitol, Pacheco y Elena Garro. Observa "una nueva posibilidad" en la narración de fiestas, viajes y relación de amigos, donde — sin duda alguna — es la generación de la Casa del Lago la que brilla en la realidad y en la ficción. Escriben historias sobre el amor-desamor y el deterioro de las parejas Inés Arredondo ( $\mathrm{La}$ señal), Juan García Ponce (Imagen primera y La noche) y Melo (Los muros enemigos). En unión con Salvador Elizondo, abordan libremente el humor, el cuerpo, el sexo, la sexualidad; las mujeres, a su vez, se refieren a la sensualidad, el incesto y la perversión. Otros escritores, como Pacheco (El viento distante), Elizondo (Narda o el verano) y Dávila (Música concreta), procuran lo misterioso, lo siniestro y el acercamiento a lo fantástico. La intertextualidad se manifiesta en Dávila con respecto de Cortázar, en Pacheco con Arreola, en De la Colina con Rulfo y en Elizondo con Borges, que lo encamina a la metaficción. Los escritores de este período se desplazan hacia personajes de la clase media, en el ámbito doméstico o en el de las oficinas. En sus estrategias narrativas aparece el tránsito del cuento tradicional hacia el "experimental": por ejemplo, De la Colina borra la procedencia de la enunciación. La ensayista detecta la existencia de cuentos canónicos (en libros ya mencionados) y cuentos proféticos, que anticipan los de violencia, terror y muerte como en Melo, "Los amigos"; Dávila, "El desayuno", y Pitol, "Tiempo cercado". Concluye su estudio a manera de paradigma del período, con Inés Arredondo, la cuentista de la generación de la Casa del Lago, "que se entregó a la búsqueda del cuento perfecto".

Apartado de la tónica acordada por el resto de los investigadores, Zavala propone una antología comparativa entre cinco creadores de los tardíos años sesenta y sus herederos veinte años después, tras elegir el criterio de "prefiguración del cuento posmoderno" para su integración por lo que, a pesar de "su importancia", excluye, enumerándolos, "algunos títulos esenciales": Elizondo: Narda o el verano más El retrato de Zoe y otras mentiras; Pitol: Los climas más No hay tal lugar; Valadés: Las dualidades funestas; Juan de la Cabada: La conjura y otros cuentos; Poniatowska: Los cuentos de Lilus Kikus; Tario: Una violeta de más; Ramón Rubín: Las cinco palabras; Pacheco: El viento distante y otros relatos; Revueltas, El apando; Juan Manuel Torres: El viaje; y Julieta 
Campos: Celina o los gatos. Los cinco libros de "carácter irónico" son: Jorge Ibargüengoitia: La ley de Herodes; José Agustín: Inventando que sueño ("Cuál es la Onda", su "cuento paradigmático"); Monterroso: La oveja negra y demás fábulas; Sergio Golwarz: Infundios ejemplares; y René Avilés Fabila: Hacia el fin del mundo. El humor del primero, con narrador autoironizado, trasciende en Bernarda Solís: Mi vida privada es del dominio público y Rafael Pérez Gay: Me perderé contigo. "[L]os juegos con el lenguaje" y los "de clase [y cultura popular]" del segundo se prolongan en Dante Medina: Niñoserías, Óscar de la Borbolla: Las vocales malditas, Emiliano Pérez Cruz: Borracho no vale y Guadalupe Loaeza: Primero las damas. El tercero, los "juegos con el sentido común [ironía alegórica]", lo heredan Fabio Morábito: La lenta furia y Guillermo Samperio: Cuaderno imaginario. La "serie de cuentos" del cuarto modelo, con antecedentes en Nellie Campobello y Arreola, reviven con "impulso irónico" en Martha Cerda: La señora Rodríguez y otros mundos y Ángeles Mastretta: Mujeres de ojos grandes. El quinto, en que se integran el humor, lo fantástico y la reflexión social, desemboca en Luis Humberto Crosthwaite con Marcela y el rey al fin juntos, cuyo registro lingüístico proviene de la fronteriza Tijuana, "en cuyos cuentos se reescribe la historia de la patria desde una perspectiva irónica”. El especialista comunica que durante el lapso 1966-1969 existen dos tendencias: en una se juega con los elementos tradicionales - que contribuye al desarrollo de la crónica urbana-, y en la segunda, se halla el cuento intimista y la experimentación vanguardista de la generación de la Casa del Lago. Añado que durante el período también escribieron cuento, entre otros autores: Humberto Guzmán, Juan Tovar, Esther Seligson, Jorge Arturo Ojeda, Max Aub y Orlando Ortiz.

\section{LOS AÑOS SETENTA:}

\section{Laura Cázares, Russell M. Cluff y Vicente Francisco Torres}

Cázares, que dedica su estudio a su maestro y amigo Sergio Pitol, en cierta medida se guía por el modelo creado por Luis Leal, así que en dos o tres líneas compendia datos personales desconocidos que contribuyen a esclarecer el contexto cultural del escritor; tras ello, describe la obra, transcribe la crítica de importancia y a continuación, en forma concentrada, emite su juicio; dicha estructura también refleja su expe- 
riencia en el tema pues contribuye a formar un punto de vista en el lector. La investigadora revisa por decenios a autores que nacieron a partir de 1900 y 1920, en que sobresalen, de nuevo, Monterroso con Movimiento perpetuo y Castellanos con su cuento "Lección de cocina" en Álbum de familia. Muy interesantes resultan los autores nacidos en los años treinta, porque entre ellos vuelven a destacar los de la Casa del Lago y deploro no detenerme en ellos, sino para mencionar dos textos imprescindibles: El grafógrafo de Elizondo y "El gato" de García Ponce; la razón es que deseamos prestar atención a dos escritoras y un transterrado: Ulalume González de León ( $A$ cada rato lunes), Marcela del Río (Cuentos arcaicos... para el año 3000) y Pedro F. Miret (Esta noche... vienen rojos y azules), así como a un cuentista con orígenes en la oralidad, Dámaso Murúa (El Güilo Mentiras), de Sinaloa. Después, Cázares aborda la obra de Pitol logrando en dos páginas un nutrido resumen crítico de su obra, sobre la que se especializa, para después ocuparse del chileno Hernán Lavín Cerda y de Pacheco en El principio del placer, en particular en su veta fantástica con dislocamientos temporales como en "La fiesta brava" y "Tenga para que se entretenga". Concluye este apartado con los nacidos en los años 40; entre otros: Avilés Fabila, Roberto Páramo, Rafael Ramírez Heredia, Parménides García Saldaña (El rey criollo) y Carlos Montemayor (Las llaves de Urgell). Apreciamos que el trabajo de Cázares por sí solo se califica como esmerado e inteligente no sólo por su capacidad de síntesis sino por sus aportaciones sobre la recepción crítica de las obras.

Cluff, leal discípulo de don Luis, ha dedicado su vida al cuento mexicano: en él forma parte de su identidad, pues nació en Chihuahua y aprendió el español como lengua materna. Su trabajo se convierte en un diálogo continuo entre la aceptación o el cuestionamiento razonado de aspectos teóricos que servirían o no para examinar un cuento, porque plantea que sus características diegéticas determinan los tipos de lecturas admisibles que, a su vez, conllevan el tipo de modalidad, lo cual crea una confirmación y reconfirmación circular. La extensión, 60 páginas, y sus argumentos sobre cada obra examinada convierten su trabajo en una exposición de índole magistral, pues su lectura debe realizarse palmo a palmo. Siempre por orden de importancia, enlista para cada año a qué obras presta atención. En 1974, considera a Material de los sueños de José Revueltas como el libro más valioso y procede a examinar, entre otras piezas, el polémico "Hegel y 
yo", en que establece un diálogo respetuoso con la crítica previa, para ofrecer su punto de vista sustentado con argumentos de peso. Guillermo Samperio, cuya "generación renueva la cuentística", se inicia con Cuando el tacto toma la palabra. Rescata con fundamentos un libro olvidado: Géminis de Alberto Dallal, y considera dignas de lectura las obras de Tovar y Héctor Gally. Para Cluff, 1975 es un año con altibajos debido a la presencia dominante de Sergio Galindo (de quien examina cuatro cuentos sobresalientes), de Eraclio Zepeda (de quien revisa sus elementos paródicos), y Samperio, quien ya incursiona por la metaficción. También conquistan presencia Ignacio Solares y Óscar Bonifaz. En 1976, Samperio publica Tomando vuelo y demás cuentos en que realiza innovaciones; Guadalupe Dueñas aparece con No moriré del todo, que reafirma sus dotes, y Bernardo Ruiz, con Viene la muerte: Cluff afirma que cada colección muestra cuentos de gran calidad. En el último tramo, 1977, reagrupo a los autores: dos que tienen obra previa, que son Dávila con Árboles petrificados, y Samperio, con Miedo Ambiente; otro, Ricardo Garibay, con cuentos publicados durante dos décadas en revistas, reunidos por primera vez; y los tres últimos, con el dúo de primerizos Marco Antonio Campos e Ignacio Betancourt, y José Agustín. Con ellos concluye el estudio y su autor, que ya ha expuesto la gama de modalidades temáticas y técnicas aportadas por los cuentistas, afirma que son también las de "tiempos posteriores", de modo que empieza a observarse cómo, en unión con los autores examinados por Gutiérrez de Velasco y Zavala, se están gestando y presentando obras clave u obras en espiral que alentarán a las generaciones jóvenes.

Desde su título, "Fantasía y poeticidad", Torres proporciona la clave de su trabajo y examina, entre otras, un puñado de primeras obras. "Por su limpia escritura y porque asumía el reto de lo fantástico", Agustín Monsreal con Los ángeles enfermos obtuvo en 1978 el Premio Nacional de Cuento. Con Los sueños de la bella durmiente, libro que aglutina distintos registros imaginativos, Emiliano González [Campos] ofrece un conjunto de "fantasías eróticas, escatológicas, macabras y crueles, vestidas con esplendor". Prosigue con dos escritores del norte, Jesús Gardea y Ricardo Elizondo Elizondo. El primero muestra "su innegable oficio", irrumpe en la literatura con "una prosa pausada y certera" a través de Los viernes de Lautaro y de Septiembre y los otros días. Señala Torres un aspecto interesante: la publicación de su 
primera novela, La canción de las mulas muertas, que "pondrá en crisis los conceptos de cuento y novela" porque "los cuentos de Gardea no son epifánicos", mientras en la novela trabaja con un argumento compacto cuya realización es intensa como en los relatos, por lo cual resulta difícil establecer sus fronteras, "que vayan más allá de la obviedad de la extensión”. En cuanto al segundo, no duda en externar su admiración por Relatos de mar, desierto y muerte, integrado por "apenas tres cuentos" de "voz festiva, suelta e irremisiblemente lírica". Cierra su trabajo con dos excelentes cuentistas que provienen de la costa del Golfo: Luis Arturo Ramos y Hernán Lara Zavala. Del primero expresa: "Lo que desde el principio observa el lector es una escritura sobria, que, aunque recurre a los tropos, se enfría con la pulcritud, lo sugerente y lo turbador", juicio que se constata al leer Del tiempo y otros lugares, al cual sigue Los viejos asesinos, que se caracteriza por finales abiertos o ambiguos y en que sobresale "Cartas para Julia”, que ha sido atendido con constancia por la mejor crítica. De acuerdo con Torres, "describe un atormentado triángulo homosexual femenino" a través de "una narración plácida, misteriosa y bella, donde lo que se dice en el texto es tan importante como lo que apenas se insinúa"; bajo este juicio, se infiere uno de tantos secretos que esconde la prosa de Ramos. En cuanto a Lara Zavala, que publicó en 1981 De Zitilchén, Torres lo sitúa en la herencia de El llano en llamas o Dormir en tierra, lo cual es no poco y detecta herencias de la narrativa norteamericana como las de William Faulkner, Sherwood Anderson o Edgar Lee Masters. El mapa cuentístico ofrecido por el estudioso es atractivo en grado sumo, pues sus autores conforman una pléyade que ha dejado no pocas huellas en nuestra narrativa, pero a la par, resalto a Inés Arredondo, que en 1979 publica su segundo cuentario, Río subterráneo, merecedor del Premio Xavier Villaurrutia; su obra completa ha recibido una extensa crítica dentro y fuera del país en ensayos (varios en Destino Arbirario), tesis doctorales y libros sobre su obra. Reporto, así mismo, a otros autores que escribían cuento quizá con temáticas distintas a la abordada por el crítico: 1978: Carlos Chimal, María Luisa Puga (Las posibilidades del odio), Guillermo Samperio, Esther Seligson. 1979: Sergio Galindo, Bárbara Jacobs, Samuel Walter Medina. 1980: Bernardo Ruiz, Hugo Hiriart, Sergio Pitol, Juan Villoro, Roberto Bravo, Margo Glantz, Enrique López Aguilar. 


\section{UNA REFLEXIÓN EN EL CAMINO}

Hasta este momento la exposición de los trabajos ha estado indicando que desde los tempranos años 50, las obras de Rulfo y Arreola determinaron los nuevos derroteros. Aunque el primero cancela el tema rural revelando el desencanto sobre la revolución, nutre con su lenguaje y sus técnicas narrativas al cuento posterior: Mario Muñoz ha condensado las novedosas aportaciones de ambos, en especial con respecto a Rulfo, asunto eludido cuando no se es un lector sagaz del género. Los nuevos creadores inician la transformación de sus técnicas escriturales, que entre otros recursos, persiguen más y más la ambigüedad. Resaltan la generación de la Casa del Lago y los de la "Onda", distanciados en sus fechas de nacimiento por diez o doce años, aunque es posible establecer ciertas relaciones entre ellos. Ambas generaciones abordan la sexualidad y el cuerpo, unos con acento intimista y otros desde la revelación impetuosa de su juventud. En contraste, los primeros emplean un lenguaje cuidado, nutrido en sus lecturas europeas y los segundos, un lenguaje urbano de la clase media, influido por el rock, con frases paródicas del inglés. Ambos gozan de la expansión social: en unos, fiestas de intelectuales, con alcohol, mariguana y, posiblemente, drogas; en otros, ahi nomás, fiestas de adolescentes con cerveza y mariguana. Los discursos de ambos son irónicos y experimentan con la temporalidad, pero los procedimientos sofisticados de la metaficción y la autorreferencia pertenecen casi sólo a los primeros. En los escritores de los años setenta resalta el inicio de la interrelación de géneros, refinan las técnicas aprendidas de los maestros, en particular las que rozan o penetran en la conciencia interior o que expresan lo que se conoce como el "inconsciente". El lector ya no puede permanecer pasivo, empieza a ser movilizado sitiándolo hasta lograr que acepte la batalla: paulatinamente asimila la inestabilidad, la incertidumbre y, más que nada, la ironía.

Los años ochenta: Elizabeth Corral Peña, Jaime Erasto Cortés y Miguel G. Rodríguez Lozano

Corral Peña analiza, en una aguda exposición, el tipo de obras que se manifiestan en el inicio de estos años. ¿Quién esperaría que en esos 
tiempos alguien se interesara por el amor? Corral Peña encuentra, sin embargo, sus manifestaciones en la obras de maestros y jóvenes; primero aborda a García Ponce en Figuraciones, quien emplea procedimientos de metanarración, de un "discurso ciego" que induce al lector a crear una lectura alternativa y de la ambigüedad, manejados hábilmente desde la voz que narra. Enseguida, se dedica a Ethel Krauze con Intermedios para mujeres, que por su lenguaje "fuerte, rítmico y sonoro", diálogos y "una ironía muy amarga", echa abajo las complacencias y los discursos vacíos de la mujer convencional. Monsreal se presenta con Sueños de segunda mano, libro "sombrío" en que el autor somete cada cuento a distintas estrategias "discursivas ricas y experimentales", con que logra, pese a la infelicidad que transmite, una escritura "de gran intensidad, como caballo brioso que ya no se desboca, más sigue mostrando la fortaleza de sus músculos". Con La urna y otras historias de amor de Felipe Garrido, la especialista cierra estos libros señeros para incluir a los paralelamente valiosos Enrique López Aguilar, Dallal y Humberto Rivas, cuyas obras "llevan a reflexionar sobre las libertades que se ha ido tomando el cuento y que han permitido que adquiera una flexibilidad que parecía acaparada por la novela”. Dentro del cuento creado por escritoras, se dan a conocer Brianda Domecq (Bestiario doméstico, escrito con lenguaje maduro e intertextos rulfianos en lo que respecta al corte oral), Silvia Molina, Ana Clavel, Bárbara Jacobs y Rosina Conde. Con el tema de "Escritura" incluye a Monterroso, quien en La palabra mágica destaca por la metaficción y por los intergéneros de invisible costura. Finalmente, alude a la obra de Orlando Ortiz (El desconocimiento de la necesidad), que en lo compacto de su escritura es un maestro en el tema de la violencia y la marginalidad.

Un pilar fundamental para la organización y celebración de los Encuentros ha sido Jaime Erasto Cortés, quien además integró a lo largo de su vida un importante archivo hemerográfico de índole privada, hoy bajo custodia de la Universidad Autónoma de Tlaxcala. Cortés subdividió su examen en apartados: en los dos primeros observa a las cuentistas sobre sus "iniciales pasos breves", incluye a Rosa Beltrán y María Luisa Puga, a quienes sus críticos objetaron, pero que "transcurridos los años [...] fincaron sus reales en la narrativa"; igual les ocurriría, con posterioridad, a Mónica Lavín y a Ana Clavel. Cercano a ellas, está el norteño Francisco José Amparán, con Las once y sereno y 
Cantos de acción a distancia, cuyo tema es la búsqueda de un lugar en el mundo y su fatal conclusión. A partir de este autor, Cortés asevera que "en los ochenta, los narradores vinieron del norte" y se refiere a la prosa "solar, seca, descarnada" de Gardea, tanto por De alba sombría como por Las luces del mundo; a "la elocuencia medida, a la deformación y la invención léxicas" de Daniel Sada (Juguete de nadie y otras historias), a la "vida simple" en Salvador Elizondo (Maurilia Maldonado y otras simplezas); y a la pasión y sufrimiento en Severino Salazar (Las aguas derramadas). Pero también hubo novedades entre los transterrados, como Muñiz-Huberman y Patán; a ella la ubica como una profeta transmutadora del habla con un lenguaje personal; y a él, entre otras virtudes, le reconoce su empleo profesional de los elementos narrativos, la intromisión del diálogo en la actividad del narrador, la unión pasado-presente y la prospección, que desbordan los límites del cuento sin destruirlo. Por su brevedad y economía aquilata las obras de Monsreal y Francisco Hinojosa; por el viraje impuesto a sus nuevos libros, en los que la presencia femenina es dominante, Cortés revisa a Juan Villoro (Albercas) y a Lara Zavala (El mismo cielo). Y hay quienes, a su vez, reaparecen frente al amor: ahí confluyen Krauze y Lavín, tanto como Ramírez Heredia, Alberto Huerta y López Aguilar. El período, indica Cortés, estaría incompleto sin Gente de la ciudad (1986) de Samperio.

Abordamos ahora el estudio de Rodríguez Lozano, joven investigador dedicado al cuento joven. Considera que la producción del período es apabullante: "en esos años se publicaron más de cien títulos", sin embargo, no se amilanó. De inmediato establece que en los ochenta existen poéticas que han abierto su campo de estudio, volviéndolo más complejo y, al mismo tiempo, más enriquecedor. Frente a su corpus, aprecia que "el cuento mexicano está, quizás, en uno de sus mejores momentos". Procede a referir un panorama de autores y obras, habida cuenta de que Zavala anticipó a ciertas figuras. Señala que es un período en que se empalman autores que nacieron en los años 20 (Garibay y Arredondo) y en los 60 (Ignacio Padilla, Beatriz Escalante). De ahí se deriva un hecho: en el género breve se cuantifica la vitalidad que puede acumularse bajo su tutela: también los lectores nos tornamos participantes, pues debemos avenirnos a una multitud de subgéneros: textos fantásticos, poéticos, policiales, etcétera; minificciones, cuentos breves o híbridos; de recursos y categorías estéticas como: la ironía, la 
parodia, el humor; todos reflejan espacios urbanos o provincianos al lado de mundos absolutamente ficcionales o universos eruditos y teñidos con las mitologías del caso. A pesar de su amplitud se sigue recurriendo a temas universales: el amor, la política, la crítica social, etcétera, "desde la visión más cruel y directa o desde el humor más beligerante y llamativo". El trabajo de Miguel lo muestra generoso, pues a cada paso que avanza, proporciona un puñado de autores en quienes encontraremos una o varias características que él ha agrupado con su obra respectiva en aquélla más afín con sus propuestas, subdivididas en varios apartados, de manera que no podría encontrarse una disculpa para no conocer este período, dada su riqueza editorial. De los agrupamientos aludidos, el estudioso pasa a identificar las confluencias ideológicas, concomitantes a una visión de mundo. Detecta la recuperación del lenguaje coloquial y popular, la ambientación de las zonas marginadas, sus seres e intimidades, por ejemplo, en Cristina Pacheco, Josefina Estrada o Pérez Cruz. La clase media también viene a cuento con Pérez Gay, De la Borbolla o Luis Zapata. Tijuana se desmitifica en las obras de Crosthwaite y Federico Campbell para recobrar la nostalgia de aquella ciudad de espacios familiares, calles y playas. Pero esa íntima tristeza que siempre roza nuestra cultura, pretendiendo inmovilizarla, encuentra también sus antídotos: ahí están las obras de José Luis Ontiveros, Magaly Martínez Gamba, Esther Seligson, Beatriz Escalante y Pedro Ángel Palou: "no hay duda que esas obras contienen una imaginación depuradamente intelectual", advierte el autor, "son textos que exigen un lector avieso, instruido, capaz de sobornarle al autor sus lecturas y aceptar el reto de descifrar las intenciones significativas del intertexto". Para mostrar la vitalidad de los cuentos por la eficacia es-

critural, el autor recuerda "ese inicio desbordante" del cuento "De amores" de Inés Arredondo: "Los grandes amantes no tienen hijos. Ni Isolda la de las blancas manos, ni [...]", que dejo a cada quien completar, respetando lo que Rodríguez Lozano pretende de su lector.

LOS AÑOS NOVENTA:

Ana Rosa Domenella, Pablo Brescia y Federico Patán

Domenella incorpora a su trabajo el modelo de presentación por décadas de nacimiento. Inicia con Mariana Frenk-Westheim (1899-2004), 
que en 1992 decidió publicar $Y$ mil aventuras, libro de cuentos breves y aforismos. De las nacidas en los años treinta, recoge El cantar del pecador y Alta costura, de Espejo; Aline Pettersson aborda el tema de la infancia y la memoria familiar escindida en Más allá de la mirada, en el cual Domenella se detiene por su melancolía en la palabra y la imagen de "un padecimiento que invade el final del siglo xx y el comienzo del XXI: la depresión". ${ }^{8}$ De la siguiente década están incluidas Molina (Un hombre cerca), y Mastretta por Puerto libre, que son "breves relatos, viñetas y aforismos". De las nacidas en los años 60, la crítica encuentra cambios narrativos, como en Lavín, quien se concentra en personajes de los estratos más bajos (Nicolasa y los encajes); Clavel (Amorosos de atar), que aborda vínculos difíciles, relaciones perversas y algo de ciencia ficción; o en las escritoras del norte: Cristina Rivera Garza (La guerra no importa), inclinada a ambientes y personajes sórdidos, instalados en "la cultura de la depresión" (Martínez Zalce: 1215); Patricia Laurent Kullick (Esta y otras ciudades), creadora de atmósferas opresivas, y Regina Swain en La señorita Superman y otras danzas, "que son cuentos más vitales". A continuación Domenella atiende a ellos. De los nacidos en los años 40, algunos desalientan su lectura y expone razones para su juicio, a veces en forma irónica, que dejo a la detección del lector, si bien su actitud proporciona al medio una lección de independencia intelectual cuando sabemos que lo usual es que la crítica severa se difunda a sovoz. Simpatiza con Héctor Aguilar Camín por Historias conversadas, que rescata la raíz oral del cuento, y con Marco Tulio Aguilera Garramuño, por Los grandes y los pequeños amores, en que incursiona con fortuna en la temática amatoria. Samperio y Monsreal continúan sus probados oficios en sendas obras. Cuando la siguiente promoción arriba, destacan Sada, Villoro, Enrique Serna, ${ }^{9}$ y Pérez Gay, cuyo libro Llamadas nocturnas despierta interés porque en sus cuentos incluye la materia literaria en segundo grado, como el homenaje que rinde a los libros de formación, o a la influencia de las novelas de Musil, o aparece el tema histórico con tratamiento posmoderno, como el cuento "Benito Juárez perdido en el norte de México

\footnotetext{
8 De los años 30, recuerdo a Nedda G. de Anhalt (nacida en Cuba en 1934, mexicana) por El banquete de 1991.

9 Sobre cada uno, Domenella remite a tres estudios suyos publicados en las memorias de los Encuentros.
} 
(versión hard-core)". Hacia el final de su estudio, al cual califica de "extenuante", aparece lo más interesante de su período, pues se refiere a la reedición de Las vocales malditas de De la Borbolla, a las obras de Humberto Rivas, Mario González Suárez y Crosthwaite; resume los temas de la "literatura basura" representada por Guillermo J. Fadanelli y de la "generación de los enterradores", así denominada por Celso Santajuliana y Ricardo Chávez Castañeda, en que se encuentran los del "Crack" - el propio Chávez, Jorge Volpi, Pedro Ángel Palou, Ignacio Padilla y Eloy Urroz- de quienes Fadanelli se mofa llamándoles "los del 'Frac'", por haber accedido a cargos diplomáticos. Concluyo: no puede ignorarse a ningún autor que Domenella haya abordado en su exhaustiva y sugerente exposición.

El ensayo de Brescia, sobre el período 1994-1996, se constriñe a: Técnicamente humanos, de Cecilia Eudave, y Cuentos para ciclistas y jinetes, de Adriana González Mateos, sólidas cuentistas. De acuerdo con el crítico, desde el primer cuento de Eudave, se encuentra un "protocolo de lectura" que "provee una matriz temática y formal", la cual subdivide en dos ejes no paralelos, que son: el de la posibilidad (que se juega en lo "gótico") y el de la cotidianeidad extraña, relacionados en forma intratextual. También en González Mateos existe un marco de lectura que plantea la dialéctica cotidianeidad-imaginación con tres vertientes: bien los relatos "animalizan" narración y vínculo amoroso, bien la sexualidad es un juego imaginativo dentro de la rutina, bien se crean metaficciones lúdicas. El análisis proporciona ciertas claves: aunque las autoras han leído a Borges, sus formas lúdicas provienen de Cortázar; lo anterior permite al crítico caracterizar sus obras como una "metaficción light" porque plantean "en clave absurda lo sublime y lo ridículo que puede resultar escribir". Los textos desafían la idea convencional de realidad y, sobre el rubro "mujeres", punto de llegada más que de partida, afirma que "siguen estando al margen", en la resignificación de "margen" como provecho o "ganancia". En relación con el período y sus obras, la importancia de Mantis religiosa de Mauricio Molina y Los límites de la noche de Parra, fue anticipada por Vicente Francisco Torres (2004: 255), quien, respetuoso del corpus de cada especialista, no los abordó. Agrego, observadas otras ausencias, algunas obras que también nutren el lapso: ${ }^{10}$

${ }^{10}$ Russell M. Cluff enlista no menos de 110 obras (1997: 166-170). 
1994: De la Borbolla: El amor es de clase; Rosina Conde (Premio Gilberto Owen 1993): Arrieras somos... y Embotellado de origen; Anamari Gomís: La portada del Sargento Pimienta; Lara Zavala: Después del amor; Montemayor: Operativo en el trópico; Monterroso: Sinfonía concluida; Lazlo Moussong: Tórrido quehacer; Pérez Cruz: Noticias de los chavos banda; Ramírez Heredia: La media vuelta; Alejandro Rossi: Diario de guerra; Alberto Ruy Sánchez: Cuentos de Mogador; Pablo Soler Frost: El sitio de Bagdad; Naief Yeyha: Camino a casa.

1995: Héctor Alvarado: Enciclopedia para ciegos caminantes; Amparán: Es otra la felicidad; Escalante: Fábula de la inmortalidad; Fadanelli: Terlenka, doce relatos [...]; Fuentes: La frontera de cristal; Gardea: Dificil de atrapar; Hinojosa: Memorias segadas de un hombre en el fondo bueno y Un taxi en L.A.; David Martín del Campo: Los hombres tristes; Ignacio Trejo Fuentes: Loquitas pintadas.

1996: Roberto Bravo: Lo que quedó de Roy Orbison; Ignacio Padilla: Últimos trenes; Héctor Perea: Océano de colores; Víctor Hugo Rascón Banda: Volver a Santa Rosa; Eusebio Ruvalcaba: Clint Eastwood hazme el amor; Francisco Segovia: Abalorios y otras cuentas; Alejandro Toledo: Atardecer con lluvia.

Proseguimos ahora bajo la guía de Federico Patán. Para integrar su ensayo tomó en consideración el desenvolvimiento de las escritoras y la confluencia de varias generaciones delimitadas por De la Colina con Tren de historias, una "curiosa propuesta [...] posmoderna", y por Alberto Chimal (1970) con Gente del mundo, "libro sin duda lúdico", "el más singular de los que he examinado" sobre el que señala sus aportaciones. Constata que "la cuentística mexicana [...], se ha ido alejando del realismo mimético" y que a partir de la generación de la Casa del Lago se enriquece con la variedad de su escritura para trabajar textos góticos, fantásticos, inusitados o absurdos, al lado de "los meramente realistas". Patán se propuso detectar estos mundos a través de los lenguajes con que se han realizado: así integra progresivamente a varias generaciones. Por ejemplo, en Lavín existen personajes afines a los de Espejo, Margarita Peña o Eugenia Revueltas, que exploran la sicología femenina y que se rebelan contra patrones impuestos, pero en Lavín los personajes se enfrentan con lo insólito, por efecto de un suceso inexplicable o improbable. Muñiz-Huberman se distancia de ese 
aire de familia: en Las confidentes flota un aire de literatura popular y clásica, pero lo particular es que "el libro enfoca más que nada el problema de la violencia", agudizado por el "sentimiento" del desarraigo y porque expresa con vehemencia el "choque de culturas" y "la incomprensión de lo ajeno" en su doble vertiente. Sea en lo físico o en lo espiritual, la violencia también se descubre en Tierra de nadie de Eduardo Antonio Parra, a la que suma una poética de la miseria; reconoce en él su oficio y mano segura, aunque alguna vez se haya distraído en el "trozo de vida". La nómina de autores que le tocó examinar a Patán es privilegiada: Mauricio Carrera abre el mundo de los fracasados con La viuda de Fantomas; prosiguen en ese tema: Villoro con La casa pierde, "para mí su mejor libro de cuentos"; López Aguilar, con Juguetería, es lúdico y violento a la vez, finalmente subversivo; Mario González Suárez quien explora lo oscuro del ser humano en El libro de las pasiones; Antonio Tenorio Muñoz Cota en No invoques mi nombre en vano, que muestra toques góticos y aproximaciones a lo fantástico; David Toscana (Monterrey, 1961), a quien la crítica literaria reconoce su talento, incluso en el ámbito internacional, con Historias del Lontananza, que presenta personajes en derrota, cuarentones y acorralados por la situación económica. Luis Arturo Ramos en La señora de la fuente y otras parábolas de fin de siglo, revela la "ironía que se deleita en la crueldad, pues se establece una visión del mundo que asegura la imposibilidad de darse un asomo de equilibrio en la vida que se lleve". Según avanza en sus historias se percibe que en la penumbra de significados que el libro encierra, entre ellos cierto humor negro, uno es el que se impone: "la vida es caprichosa y suele entretenerse en hostigar a las personas". Con el dominio que Federico Patán posee respecto del género breve, en su repaso de cada autor se revelan las características de la forma actual del cuento, lo cual constituye una lección magistral.

EN EL UMBRAL DEL SIGLO XXI:

Sara Poot Herrera y Alfredo Pavón

Poot Herrera declara que su trabajo de investigación, "que casi toma los cuentos de las manos de los cuentistas", ha sido iluminado por la concesión del Premio Príncipe de Asturias de las Letras a Augusto Monterroso, en el año 2000. El que Tito haya declarado en su discur- 
so de recepción que "el cuento es un género que ha venido siendo relegado por las grandes editoriales, por algunos críticos, y aun por los mismos lectores", provoca que la autora revise las formas cualitativas de la lectura a través de los argumentos de Carlos Monsiváis, Morábito, Pitol, De la Colina y Toscana, para aludir, también, a lo que los propios cuentistas, entre ellos Ana García Bergua, transmitieron en sus intervenciones en los Encuentros a partir del año 2000: cada uno expresa una poética del cuento. El trabajo de Poot es, en su extensión y en los insólitos aspectos que estuvo persiguiendo, la puesta en tinta de un estado del arte del cuento mexicano, pues revisa, valora, critica el contexto comercial del género, el de los estímulos, asesorías y organismos e instituciones que lo promueven y lo difunden desde la mera hoja de papel hasta la intimidad de la electrónica, como el sitio Ficticia o los distintos blog que se abren a voluntad. La contribución más importante para resolver el problema de la difusión del cuento lo ha constituido el proyecto Mortiz-Planeta, iniciado en 1999, que encarga año tras año a un cuentista mayor (Lara Zavala, De la Colina, Jacobs, etc.) la recopilación de Los mejores cuentos mexicanos; Poot, sin embargo, objetó con ironía demoledora la visión de género — que no del género- que Serna expuso en la edición de 2000. Sobre la materia propiamente del cuento, la especialista transmite el contenido de cada edición, mencionando la fuente original y así establece cuáles son las revistas y suplementos que apadrinan al género. Para actualizar a sus lectores, elaboró un avance de lo que después podría convertirse en una real Bibliografía con las colecciones de autor y antologías generales o por autor, para cada año de los cuatro que abarca, por ello, afirmé al inicio que Cuento muerto no anda es un libro al día. Este avance, primer paso para cualquier estudio crítico, le ha servido para aludir a la obra de los siguientes escritores en el 2000: De la Borbolla (Dios sí juega a los dados); Hinojosa (A golpe de calcetín y Un tipo de cuidado); dentro de la cuentística más radical, juzga que Fadanelli, editor de la revista Moho, en Más alemán que Hitler es un epígono de Philip Roth y de Bukowski. Una autora que manifiesta nuevas propuestas con su literatura, como "poner en la punta de los dedos dos culturas e imprimirlas en sus cuentos" es Rivera Garza, en particular con respecto de Ningún reloj cuenta esto (2002). Sobre Tlapalería, de Poniatowska, juzga a "Coatlicue" un "cuento con registros insospechados de mito e historia", con una figura femenina "que trasciende al siglo XXI investi- 
da de una nueva sexualidad". Se despide de sus autores con el reconocimiento a las obras de Salazar (Cuentos de Navidad) y dos libros del año 2001, Beatriz Graf (Contra nadie en la batalla), y Clavel (Paraísos trémulos). Como distinciones estilísticas del cuento de inicio de siglo, aprecia la incertidumbre, lo transtextual a semejanza de la cuentística gay transexual, la exploración de realidades como tal o como "virtuales", la emergencia de una literatura del desamparo, la violencia, y de un nuevo mapa literario en las fronteras geográficas, sobre todo en la del Norte. También aparecen nuevas sexualidades como en las obras de Miriam Mabel Martínez y Édgar Reza. Las setenta y tantas páginas de este estudio, pletóricas de rutas que sentimos no recorrer una por una, nos dejan una menuda tarea, y en ella, lo primero sería cuestionarnos sobre nuestro propio estado del arte en tanto lectores de cuento.

Distinguido por la amistad que le brindó don Edmundo Valadés, Alfredo Pavón participó en los quince Encuentros de Tlaxcala. En unión con sus colegas de la Universidad y sus diligentes alumnos, no sólo auxilió en su coordinación, sino que fungió como un eficiente y puntual editor. Para este volumen, el crítico preparó, además del prólogo, una exposición sobre las diversas antologías que sobre el cuento mexicano se han generado desde el siglo XIX. En razón de que Cuento muerto no anda es una propuesta sobre la segunda mitad del siglo Xx, transmitiré algunos comentarios sobre dicho período, sin dejar de reconocer la utilidad integral de su trabajo, en particular la bibliográfica, siempre recurrida en la investigación. La lectura debe emprenderse siguiendo el texto, y la consulta paralela de la lista de antologías, por decenios. Durante los años cincuenta aparecen Los mejores cuentos policiacos, de María Elvira Bermúdez, cuentista en ese género; el Anuario del cuento mexicano del INBA y una selección de Emmanuel Carballo, Cuentistas mexicanos modernos, a quien se debe la primera Bibliografía del cuento mexicano del siglo XX. En los años sesenta, Efrén Hernández, Ramón Rubín, Martínez Sotomayor, Tario, Rafael Solana, Arreola, Rulfo y Revueltas aparecen continuamente en los subsecuentes Anuarios y en El cuento mexicano del siglo XX. Entre las formas trabajadas se encuentran los bestiarios paródicos de la sociedad urbana e industrial; el cuento-ensayo y el minicuento, que heredan tanto los de la generación de la Casa del Lago como los transterrados. Los libros colectivos son Diez cuentos mexicanos contemporáneos, 30 cuentos de autores mexicanos jóvenes, Narrativa mexicana de hoy, y Narrativa joven de México 
con prólogo de Glantz y selección de Xorge del Campo. Pavón detecta el juego de las voces narrativas, incrustaciones de microhistorias dentro de un evento central, las diégesis circulares, abiertas, ambiguas, hibridación discursiva, etcétera. En los años setenta "el experimentalismo fue una de las marcas de quienes se iniciaron en el movimiento de la Onda”. Pavón describe cada uno de los recursos, para concluir que se trata de "una cuentística multiforme y variada que aún aguarda su estudio pertinente". La antología más comentada de la época fue, sin duda, Onda y escritura en México. Jóvenes de 20 a 33, con prólogo de Glantz. La Antología de cuentos mexicanos de María del Carmen Millán, se convirtió en libro de formación para preparatorianos y jóvenes universitarios. Aurora Ocampo dio un paso adelante con Cuentistas mexicanas. Siglo XX. El interés de los antologadores (y las editoriales) se disparó a partir de los años ochenta: aparecieron casi cincuenta obras y setenta para la década siguiente. Entre las primeras están Los cuentos de "El Cuento" de Valadés; Lo fugitivo permanece. 21 cuentos mexicanos al cuidado de Monsiváis; La novela corta en el primer romanticismo mexicano, de Celia Miranda Cárabes y Jorge Ruedas de la Serna; El cuento. Siglos XIX y XX, de Jaime Erasto Cortés y Cuentistas de la Revolución Mexicana de Xorge del Campo, rescate valiosísimo de múltiples autores desconocidos. Entre aquéllas de los noventas, destacan sobre todo las de las narrativas regionales, las de géneros específicos como el policiaco, erótico, triste, de seducción, humorístico, etc., o las de jóvenes valores en la provincia, como las del Programa Tierra Adentro. Ante producción tan extensa, Pavón declara que ese testimonio "alienta a quienes niegan la defunción del cuento".

"Tanto cuento cuenta tanto" que, para concluir, me referiré a algunas de las significativas aportaciones de Cuento muerto no anda, entre ellas, el ánimo de conformar una historia del cuento mexicano de la segunda mitad del siglo $\mathrm{XX}$, que ignoramos si desde un punto de vista estético terminó en el año 2000 o concluyó algo antes o prosigue todavía: la contigüidad en tiempo nos impide fijar ese horizonte. Lo que sí conocemos es que cada libro de cuento abordado en los estudios ha sido refrendado por los lectores, especializados o diletantes comunes del género, y que, aun en la amplitud con que cada crítico nutrió lo suyo, existen libros que ya no pudieron ser abordados por los límites propios del tiempo o del volumen mismo: este estudio también lo sufre en lo propio. En lo que toca a los críticos que se esmeraron en 
recoger textos olvidados o meramente desatendidos por reseñas o la crítica previa, encuentro su disposición de considerar a la literatura no como la exclusiva suma de obras señeras, sino "como un sistema de obras unidas por denominadores comunes, que permiten reconocer las notas dominantes de una fase", según ha advertido el eminente crítico Antonio Candido (1996: 307-322). Dentro de este sistema tuvo cabida el reconocimiento de las escritoras y su ascenso de género en el género y, en paralelo, la emergencia rica y singular de los cuentistas en el norte de México, la inclusión de los escritores transterrados y la de los cuentistas hispanoamericanos avecindados en México, así como la valoración de los jóvenes talentos que fueron transformando la faz del cuento o que la están realizando casi en este momento. Consideramos que el cumplimiento y el adelanto de la tarea fueron altamente significativos, mismo si por causas ajenas no haya podido alcanzarse la totalidad, primero, porque estaba de por medio la localización de muchos libros de cuentos que no existen en los acervos públicos, pero sí en bibliotecas particulares y, después, porque una empresa de tal envergadura requeriría del apoyo académico y económico de varias instituciones: podría asegurar, incluso, que la mayoría de los críticos aportó lo suyo propio para conseguir sus materiales y dedicó tiempo de su descanso o vacaciones para cumplir con el compromiso asumido. Aunque los especialistas tuvieron la libertad de establecer sus parámetros de trabajo, en la lectura de la obra se advierte que el grupo de investigadoras generó un consenso en torno a las prioridades del proyecto, adecuando su metodología a las particularidades encontradas; se sabía, además, de su mutua solidaridad para obtener las fuentes originales, lo que las ayudó a redondear sus exposiciones durante el XV Encuentro. Entre las tareas futuras, queda el rescate de piezas valiosas, que por la índole de su publicación no se editaron en un libro, por ejemplo, don Luis Leal encontró un cuento de Frida Kahlo, según lo ha informado Sara Poot Herrera, y en las páginas de México en la Cultura ha sido localizado por Elena Urrutia un cuento de Tita Valencia que el propio Juan Rulfo entregó a la mesa de redacción del suplemento.

Es advertible que la edición de este libro es, por su contenido, a la vez una obra de consulta y de estudio para distintas capas de lectores, de ahí su gran valía: sirve tanto a investigadores y maestros como a estudiantes y público en general, a editores, críticos y periodistas culturales y es seguro que un buen número de bibliotecas del país y del ex- 
tranjero desearán incorporarlo a sus fondos. Desafortunadamente el tiraje de Cuento muerto no anda consta de sólo 500 ejemplares, debido a que su extenso contenido consumió el presupuesto destinado a papel, impresión y encuadernación (en verdad un destino arbitrario) y aunque las editoras universitarias no se distinguen por la distribución ágil, es factible que se agote en poco tiempo. Habría entonces que preguntarse si en el futuro existirá la posibilidad de su reedición —incluso por una casa con alcance internacional-, para lo cual sugeriría primero, la sustitución de su título y portada, para que a la obra se le identifique como lo que es: una historia del cuento mexicano de 1950 a 2003; segundo, que los períodos a los cuales les hizo falta cierta amplitud informativa y crítica se expandieran en armonía con el resto de la obra y en beneficio de diletantes y estudiosos; y tercero, que pudiera contar con un índice de autores y obras que facilite su consulta, ausencia justificada en esta edición por la celeridad con que se imprimió y porque no ignoramos que se requieren meses para su realización.

Finalmente, los lectores de esta obra indispensable debemos un reconocimiento a cada uno de los investigadores. Algunos formaron parte de los Encuentros desde su inicio; otros se identificaron a través de sus varias participaciones y otros, denantes, ya se habían especializado en el cuento; un grupo sin duda entusiasta y con las mejores armas críticas como lectores del género: por ellos y por las consideraciones expuestas a lo largo de la reseña, es positivamente palpable la tarea que la Universidad Autónoma de Tlaxcala, el Instituto Nacional de Bellas Artes y el Instituto Tlaxcalteca de la Cultura realizaron durante quince años: fue un modelo institucional explorado como en escasas ocasiones se haya visto en nuestro país, con un resultado exitoso en el ámbito histórico-cultural, literario y académico - la muestra está en sus publicaciones-, que anunciaba la posibilidad de convertirse en un único y privilegiado centro de estudio y divulgación sobre la materia, incluso para visitantes extranjeros. Por todo ello, deploramos la decisión de las autoridades respecto de la conclusión de los Encuentros, cuando se apreciaba su consolidación porque había generado un sustantivo cúmulo de reflexión y diálogo que, al mismo tiempo, nutría a los estudiantes universitarios — que acudían también desde otros estados- y ellos a los especialistas; con su presencia se tributaron, además, homenajes a don Luis Leal en 1989, a Helena Beristáin en 1992, a don Edmundo Valadés en 1993, a Seymour Menton en 1997 y a 
Jaime Erasto Cortés en 1998. Entre otras intenciones gestadas en los Encuentros, se había previsto la adaptación de un espacio destinado a la futura apertura de una biblioteca especializada en cuento mexicano, pues contaba con el ofrecimiento de sustantivas donaciones particulares, que incluso hubiera servido para integrar un acervo especial con los cientos de libros o "engargolados" que penosamente los críticos debieron conseguir para elaborar sus ensayos. Cuenta habida, así mismo, de que las autoridades universitarias y la sociedad tlaxcalteca brindaron año tras año a sus invitados hospitalidad cordial y esparcimiento en su histórica ciudad, en donde, además, se saboreaba la deliciosa comida regional: los testimonios en su torno siempre apuntan a que la manera de celebrar los Encuentros no tenía parangón con otros congresos o encuentros en el país.

Esperamos que en los nuevos derroteros de los entusiastas del cuento se continúe alentando la pasión por este género milenario, vital, y que, observada su labor pionera, pudieran cosechar simpatías junto con las decenas de participantes en los Encuentros, para que fuera un grupo que promoviera con su asesoría un nuevo programa de investigación, estudio, consulta y divulgación del cuento mexicano, incluso en sus relaciones con la cultura iberoamericana, ${ }^{11}$ con instituciones sensibles al rescate, registro y valoración de nuestra historia literaria.

\section{BIBLIOGRAFÍA}

Batis, Huberto. Posdata. Suplemento Cultural de El Independiente. 27 (10 de enero de 2004). 5-7.

Candido, Antonio. "Introducción". Formação da literatura brasileira (momentos decisivos)", en Conjuntos. Teorías y enfoques literarios recientes. Alberto Vital (ed.). Trad. Antelma Cisneros. México: Universidad Nacional Autónoma de México, Instituto de Investigaciones Filológicas / Universidad Veracruzana, 1996.

${ }^{11}$ La revista El Cuento fue conocida y todavía es aclamada a lo largo y ancho de Iberoamérica: don Edmundo Valadés recibía una innumerable correspondencia a la que daba respuesta en sus páginas. Todo lector mexicano que viaje a Brasil, por ejemplo, sabrá que, entre escritores y público adicto, Juan Rulfo es tan conocido como João Guimarães Rosa y que, además, recibió honores en ese país. 
Cluff, Russell M. Panorama crítico-bibliográfico del cuento mexicano (19501995). Tlaxcala: Universidad Autónoma de Tlaxcala / Brigham Young University, 1997 (Destino Arbitrario, 14).

- Los resortes de la sorpresa (Ensayos sobre el cuento mexicano del siglo XX). Tlaxcala: Universidad Autónoma de Tlaxcala / Brigham Young University, 2003 (Destino Arbitrario 21).

De Anhalt, Nedda G. El banquete. Prólogo de Horacio Costa. México: Universidad Nacional Autónoma de México / DC, 1991.

Díaz Ruiz, Ignacio, et al., Cuento y figura. Tlaxcala: Universidad Autónoma de Tlaxcala, 1999 (Destino Arbitrario 17).

Leal, Luis. Breve historia del cuento mexicano. Prólogo de John Bruce-Novoa. Tlaxcala: Universidad Autónoma de Tlaxcala / Universidad Autónoma de Puebla, 1990 (Destino Arbitrario, 2).

Martínez Zalce, Graciela. "La cultura de la depresión”, en Topodrilo. 43. México: Universidad Autónoma Metropolitana-Iztapalapa (jul.-ago. 1996).

Muñoz, Mario, et al., Cuento muerto no anda (La ficción en México). Edición y prólogo de Alfredo Pavón. Tlaxcala: Universidad Autónoma de Tlaxcala / Instituto Nacional de Bellas Artes / Consejo Nacional para la Cultura y las Artes / Instituto de Cultura de Tlaxcala, 2004 (Destino Arbitrario, 23).

Urbina Orantes, Julio César. "Al encuentro del cuento: la crítica en Tlaxcala” [Tesis]. México: Universidad Nacional Autónoma de México, Facultad de Filosofía y Letras, Sistema de Universidad Abierta, Colegio de Letras Hispánicas, 2001.

—, et al. Púshale un cuento al piano (La ficción en México). Tlaxcala: Universidad Autónoma de Tlaxcala / Consejo Nacional para la Cultura y las Artes / Instituto Cultural de Tlaxcala, 2003 (Destino Arbitrario 22).

Valadés, Edmundo. "Al rescate de Céfero", en Russell M. Cluff y otros. Cuento de nunca acabar (La ficción en México). Edición, prólogo y notas de Alfredo Pavón. Tlaxcala: Universidad Autónoma de Tlaxcala / Universidad Autónoma de Puebla / Instituto Nacional de Bellas Artes / Consejo Nacional para la Cultura y las Artes, 1991. 
